\title{
التقدم العلمى والتكنولوجى وأثره على تطور فن النحت المعامر Scientific and technological progress and its impact on the development of contemporary sculpture
}

\author{
مدرس بقسم النحت بكلية الفنون الجميلة - جامعة الإسكندرية
}

رحاب محمود بلر خميس

ملخص البحث :

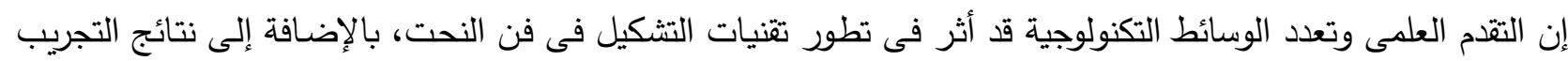

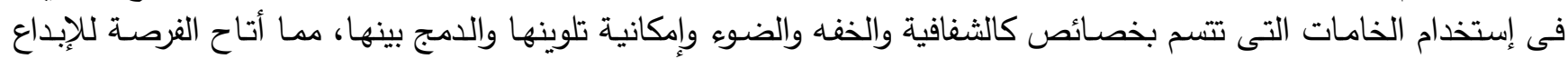

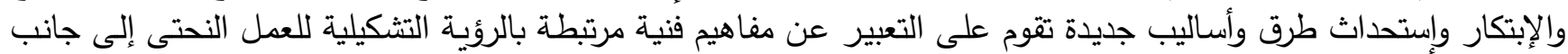

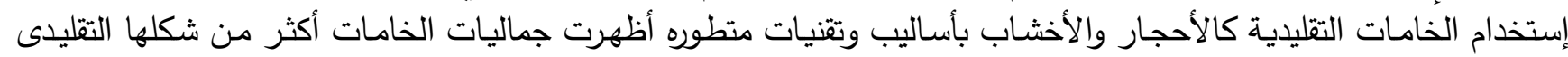
وبرؤيه معاصره، فالفن التشكيلى ليس إبداعآ تعبيرياً خالصآ لكنه إبداعآ يحتاج إلى وسائط يتجسد من خلالها الها المحتوى التعبيرى.

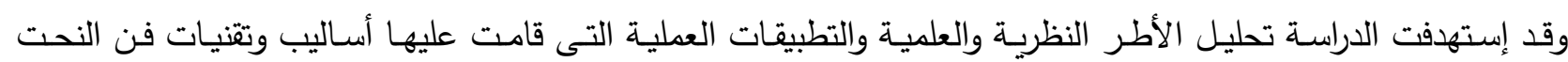

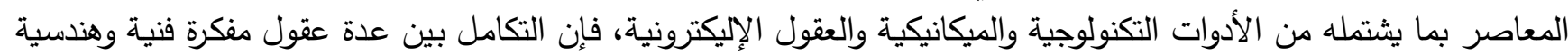

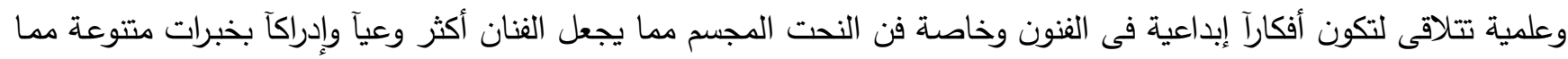
يمكنه من إستخدام كافة العلاقات ما بين التقنية والمواد والخامات واتئ والآلات.

وقد توصلت الدراسة إلى نتيجة هامة وهى أن بدون التكنولوجيا لا يتقدم العلم ولا تتسع آفاق المعرفة، وفى ظل تطبيق ونقل

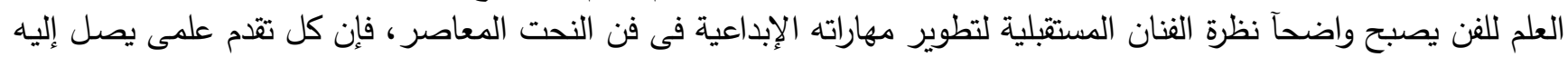

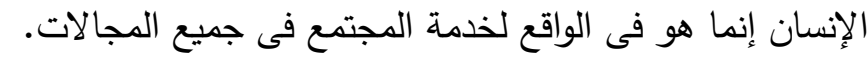

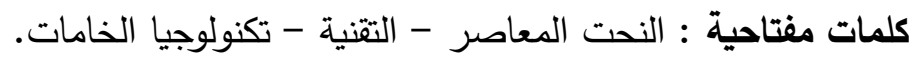

\begin{abstract}
- Abstract :
The scientific progress and the technological multimodality have influenced the development of techniques of modulation in sculpture, in addition to the results of experimentation in the use of raw materials characterized by transparency, lightness and light and the possibility of coloration and integration, which provided the opportunity for creativity and innovation and the development of new ways and methods based on the expression of related technical concepts with the visual vision of sculptural work, besides the use of traditional raw materials such as stones and wood with sophisticated methods and techniques that showed the aesthetics of raw materials better than their traditional form and in contemporary vision. Fine art is not just pure creativity, it is a creativity that needs means through it shapes the content of expression.
\end{abstract}

The study aimed at analyzing the theoretical and scientific frameworks and practical applications on which the methods and techniques of contemporary sculpture were based, including the technological and mechanical tools and the electronic minds. The integration between several technical, engineering and scientific minds which comes together to form creative ideas in arts especially in 3D sculpture which makes the artist have more knowledge and understanding of various experiences, which enables the use of all relationships between technology, materials, and machinery.

The study has reached an important conclusion: without technology, science does not advance and the horizons of knowledge does not widen. With the application and transfer of science to art, the future artist's vision becomes clear for the development of his creative skills in contemporary sculpture. Every scientific progress man has achieved is actually to serve the society in all fields.

- Abstract keywords: Contemporary sculpture - Technical - Materials Technology.

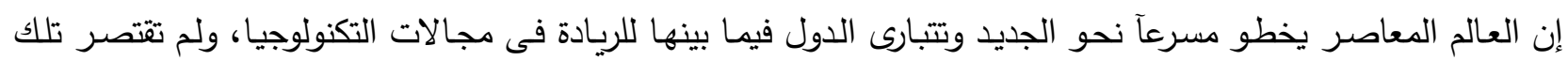

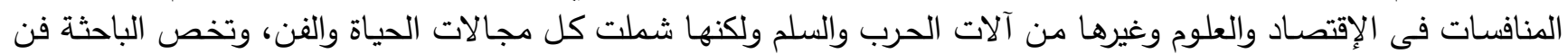

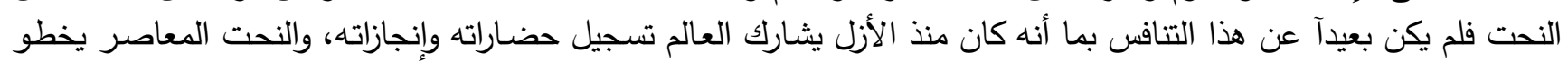

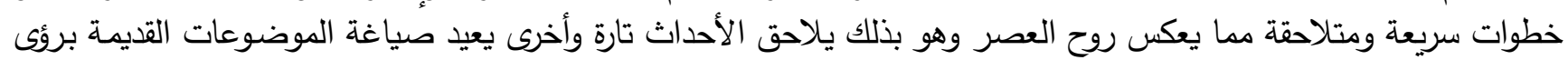


جديدة أو يقوم بالتجريب وإستخدام الخامـات الحديثة أو يعيد إستخدام الخامـات القديمة، وهذا من خـلال روح العصر والعولمـهـ وتسابق الأحداث بعضها البعض وتعدد الممارسات الفنية رغم إختلاف الجنسيات والثقافات واللغات.

لقد تحقق الكثير من التطور العلمى والتقنى خلال القرنين العشرين والواحد والعشرين، من إختراعات وإكتشافات علمية

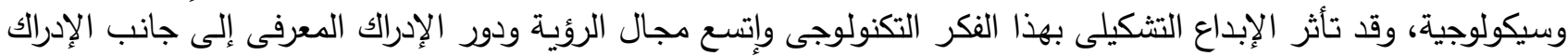

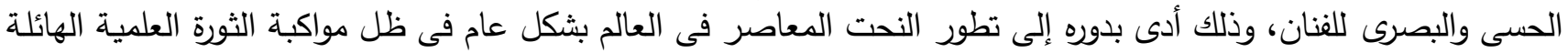

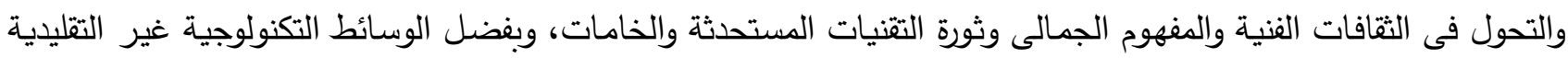

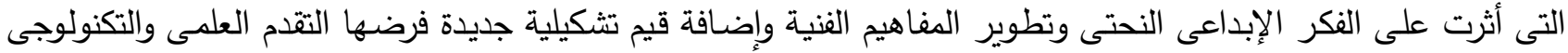
أكدت للفنان فرصته في الإبتكاروالتجريب بحريه.

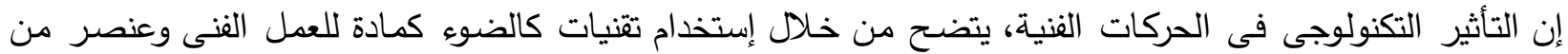

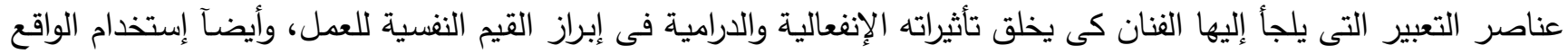

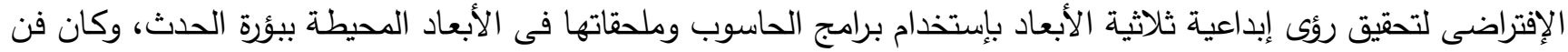

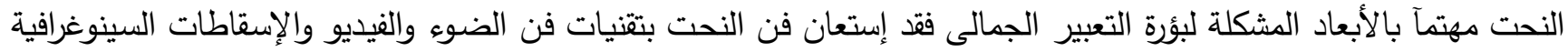
سعياً إلى التخفيف من كتلته المادية والإستعانه بالطيف الضوئى عن اللون وبتكنولوجية الواقع الإفتراضى بالإليهائيام عن اللمس،

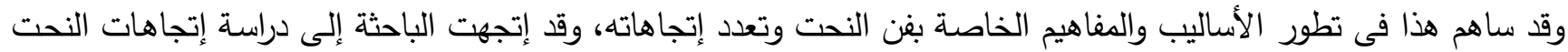
المعاصر ومدى ديناميكية العلاقة بين التكنولوجيا والخامات وفكر الفنان الإبداعى. موضوع البحث : التقدم العلمى والتكنولوجى وأثره على تطور فن النحت المعاصر .

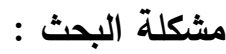
- أثر التقدم العلمى والتكنولوجى على تطور الأعمال النحتية المعاصره.

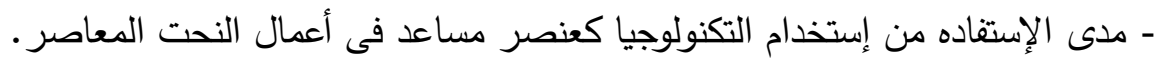
- كيفية الموائمة بين التقنيات المعاصره والإسلوب الفنى.

$$
\text { أهداف البحث : (البعاء الضوء }
$$

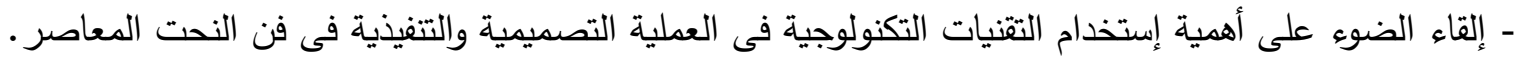
ــ البعد الجمالى والتعبيرى الناتج عن تطبيق التقنيات المعاصره والتوصل إلى مفاهيم جديدة فى مجال فن النحت.

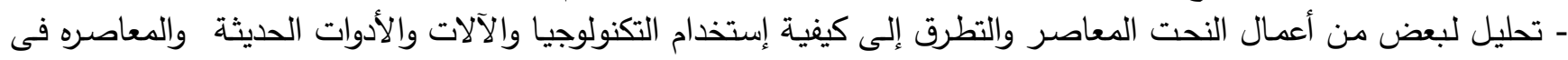
تنفيذها.

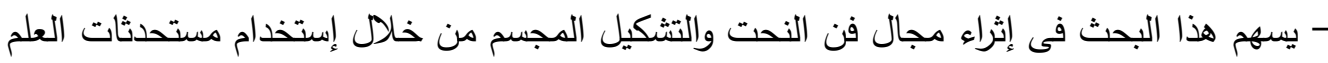
والتكنولوجيا وتوظيفها فى بناء وتثكيل منحوتات معاص فن فئرهاء

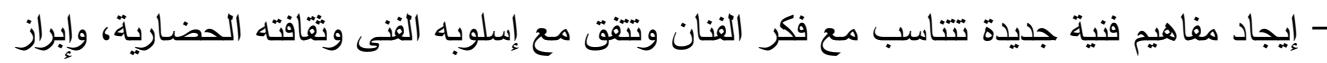

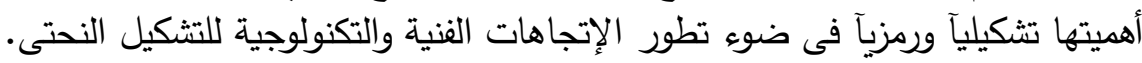

حدود البحث : - يقتصر البحث على دراسة وتحليل العلاقة الديناميكية بين العمل النحتى والتقنيات التكنولوجية المساعده فى إنتاجه.

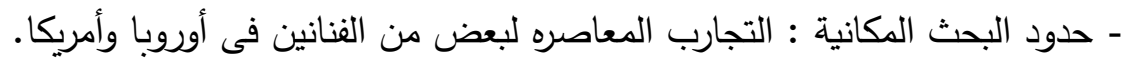
- حدود البحث الزمانية : القرن الواحد والعشرين. فروض البحث : - تقترض الباحثة أنه من خلال ما قدمه العلم والتكنولوجيا الحديثة والمعاصره من آلات وأدوات تعتبر وسائط للتعبير عن مفاهيم - تقترض الباحثة أن التطور الإبداعى يلزمه التجريب ومواكبه التقدم التكنولوجى للخامات والأدوات المعاصره مما يسهم فى إثراء فن النحت عن طريق الحلول التشكيلية الجديدة. 
- يعتمد البحث على المنهج الوصفى التحليلى ويمكن التأكد من الفروض الموضوعه لهذا البحث من خلال المحاور التالية :

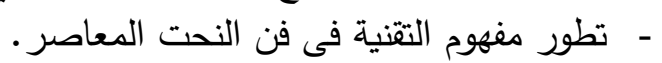

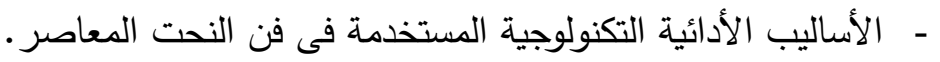

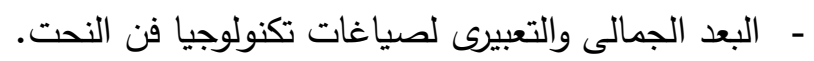

\section{المحور الأول: تطور مفهوم التقنية فى فن النحت المعاصر}

محاور البحث :

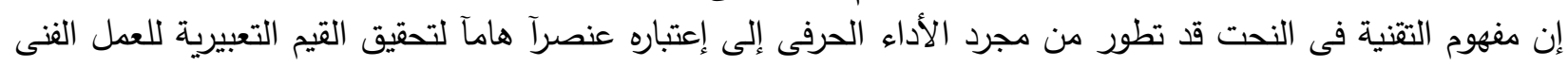

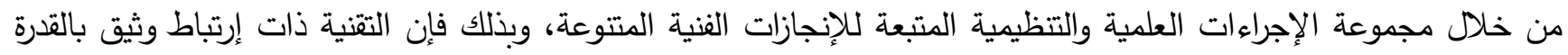

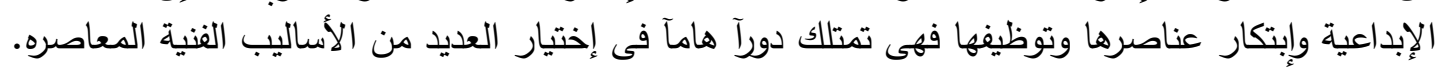

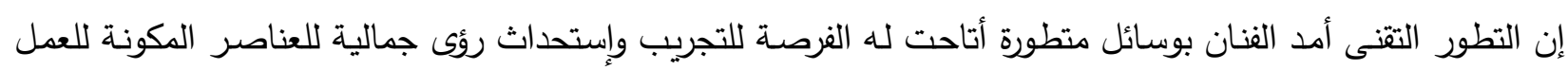

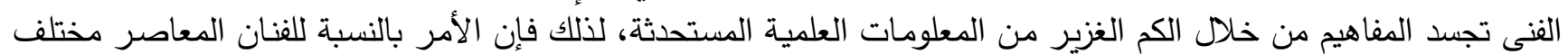

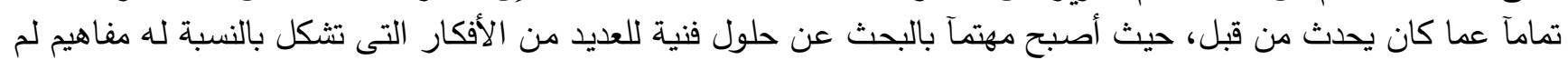

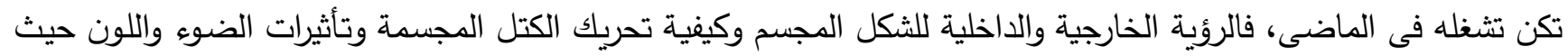

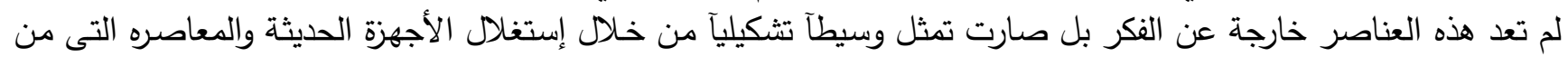

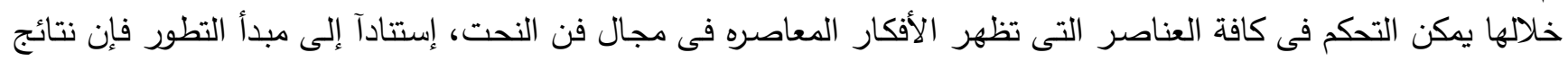

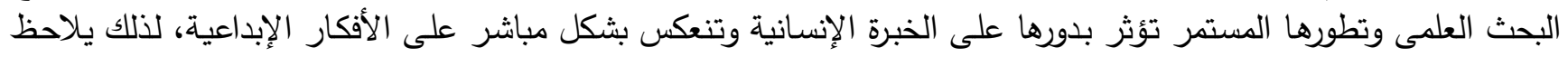

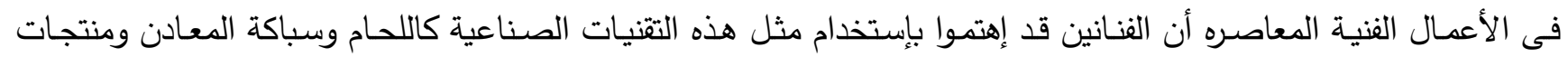

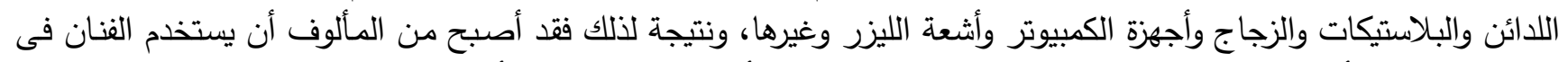

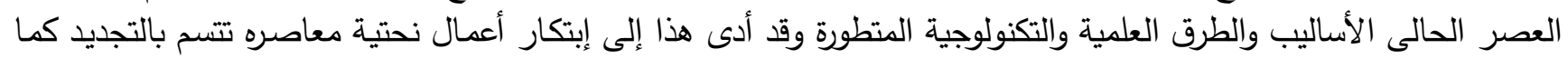

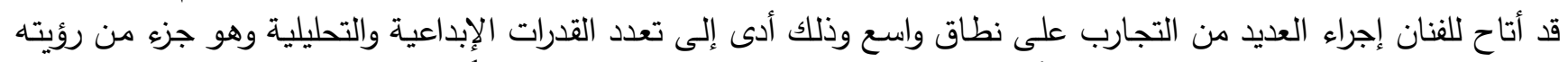

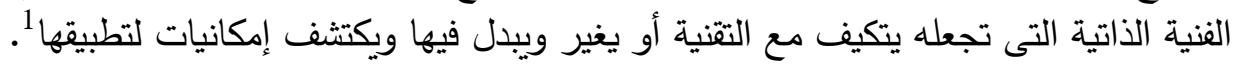

إن المزج بين الفن والتقنية أتاح تقدماً هائلاً فى التتوعات التشكيلية التى تتحرك وتصدر أصواتآ وتبعث أضواء إلى الألوان

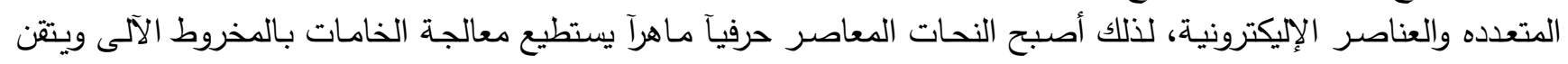

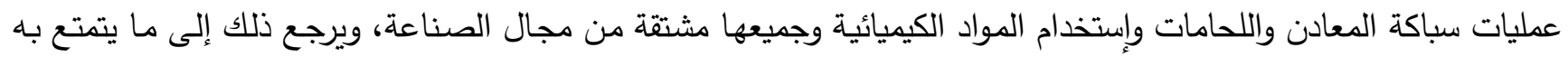

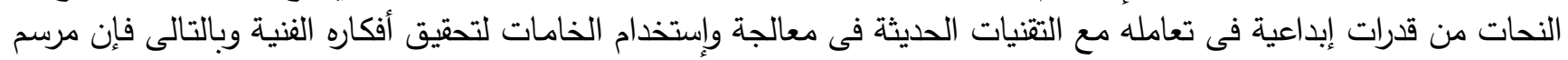

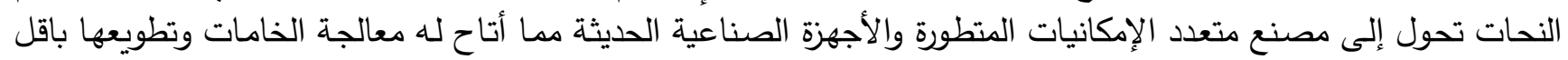

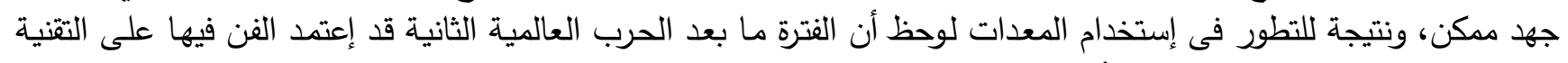

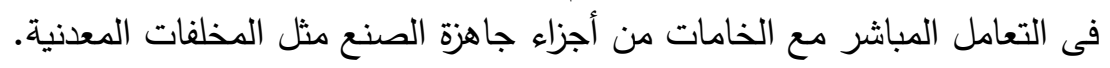

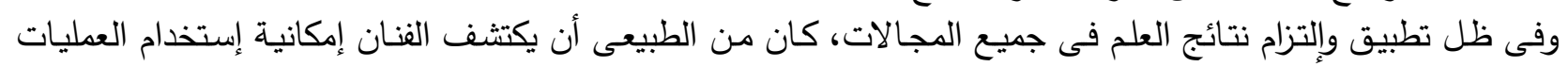

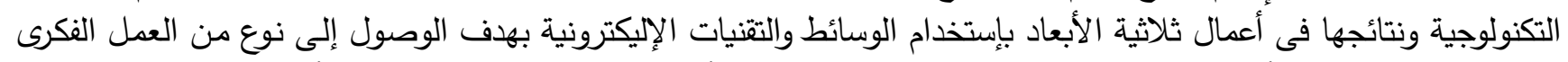

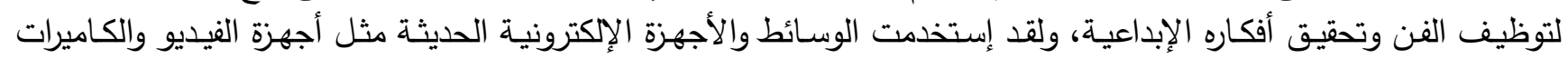

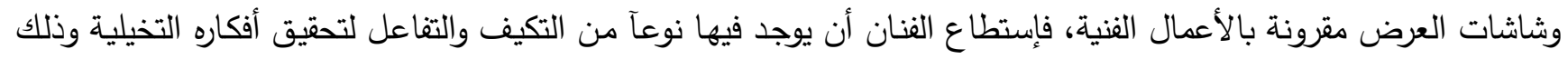

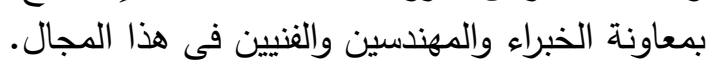

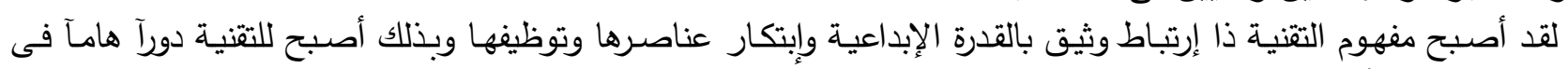

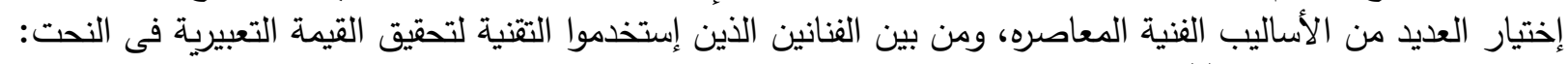

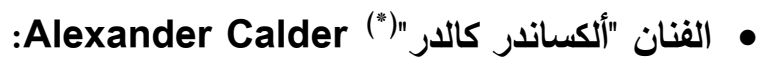

وقد إستخدم تقنية المفاصل والأوزان المتعادلة وتقوم على إبراز قيمة الحركة فى الأعمال

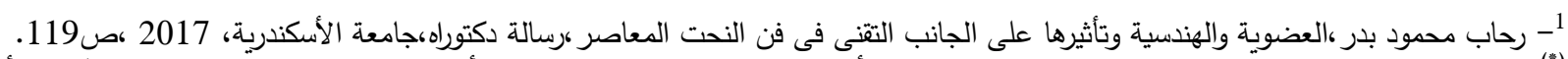

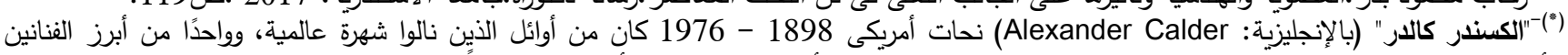

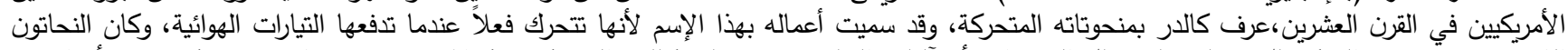

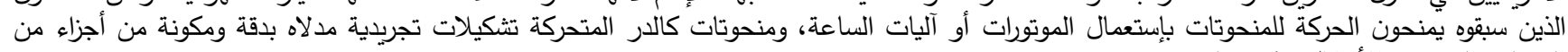




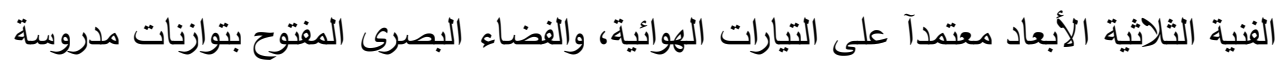

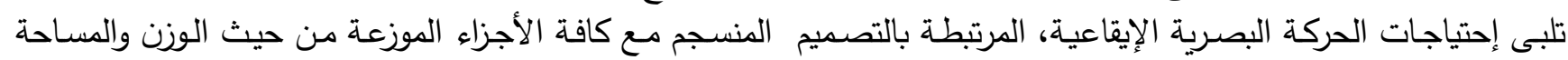

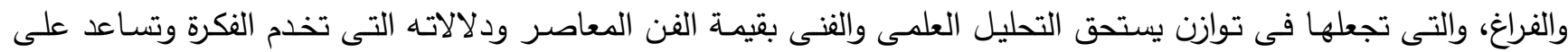

- فيديرها، كما فى شكل (1).

\section{• •}

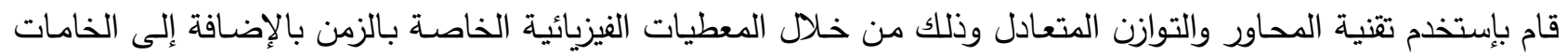

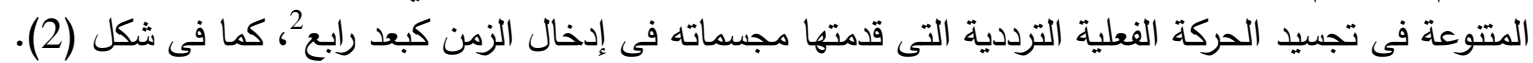
- https://vimeo.com/275147732

\section{- فيديو توضيح لهذه التقنية:}

إستخدم التجميع والتركيب والمحرك الكهربائى مما جعله يتجه للنحت الحركى الميكانيكى مع إضافة بعض المؤثرات الصوتية

كما فى شكل (3).

- فيديو توضيح لهذا العمل:

- https://www.youtube.com/watch?v=SrOA_GkRsNU

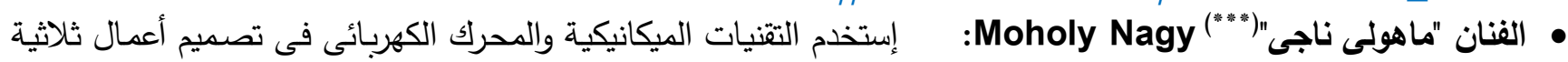

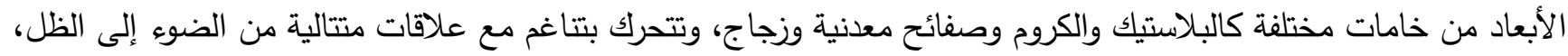

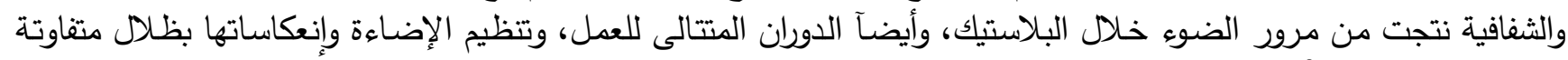

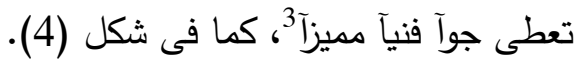

- ميديو توضيح لهذا العمل:

https://www.youtube.com/watch?v=nVnF9A3azSA

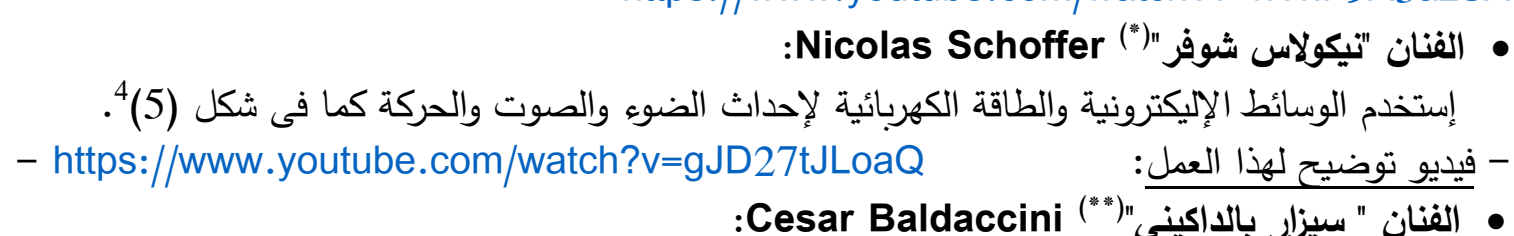

إهتم بإستخدام تقنية الضغط الضئل الهيدروليكى للأشكال سابقة التجهيز للتأكيد على البعد التعبيرى للشكل فى حالته الجديدة كعمل

نحتى مبتكر كما فى شكل (6).

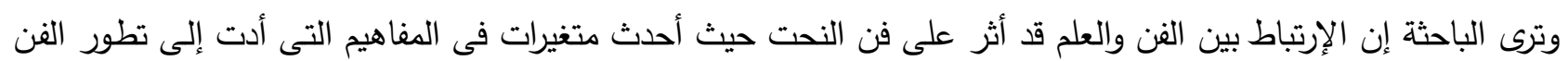

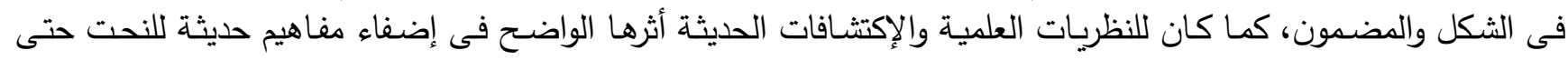

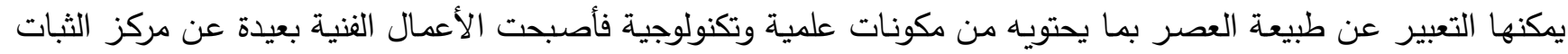

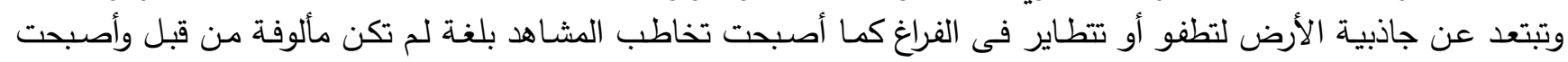

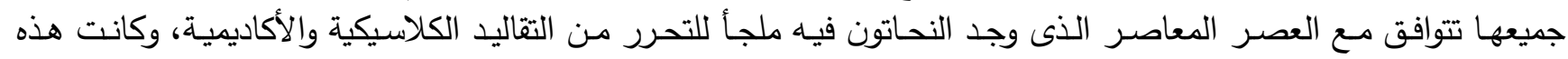

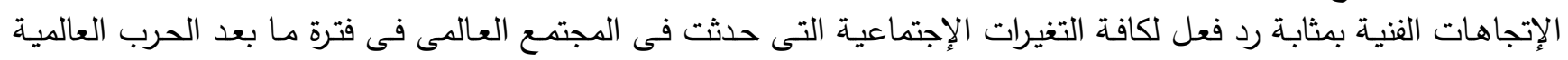

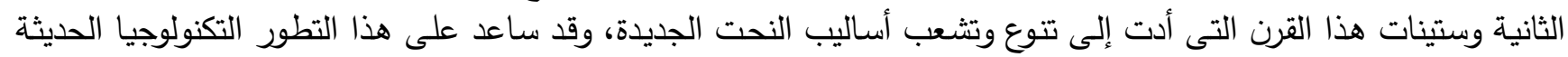
وإستخدام الطاقة الطبيعية والميكانيكية وإستغلال الطاقة الكهربائية والمغناطيسية التى إستطاع الفنان إنىان إستخدامها في أعماله النحتية

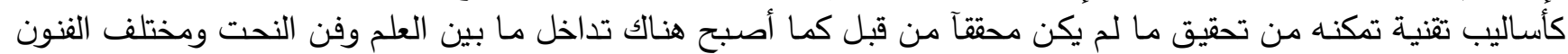

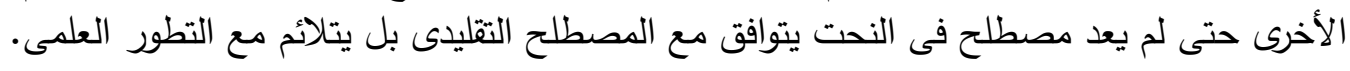

1. Cubism And Abstract Art,The Museum Of Modern Art ,New York,1936,p.197.

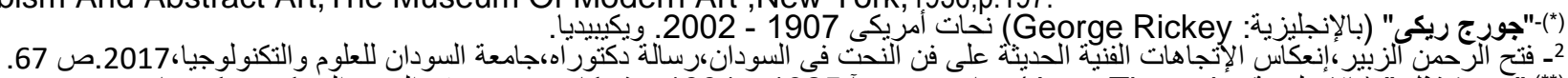

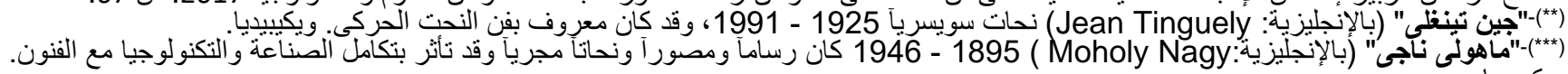

3- https://www.harvardartmuseums.org/art/299819

(*)-"نيكو لاس شوفر" (بالإنجليزية:Nicolas Schoffer) 1912 - 1992 كان نحاتاً مجرياً وقد أهتم في أعماله بالنحت الميكانيكى الحركى. ويكيبيديا.

4- http://cyberneticzoo.com/cyberneticanimals/1956-cysp-1-nicolas-schoffer-hungarianfrench/

(**)-"سيزار بالداكينى" (بالإنجليزية:1921 192 - Baldaccini Cesar 1998 نحات فرنسى.ويكيبيديا. 

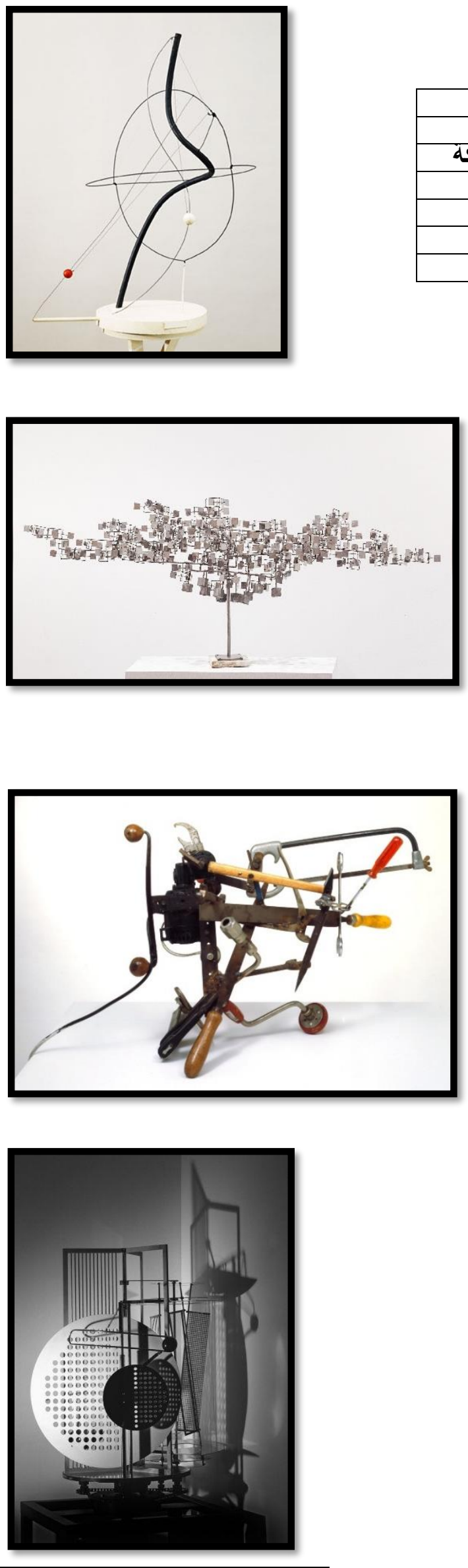

4

\begin{tabular}{|c|c|}
\hline موهولى ناجى & اسم الفنان \\
\hline $\begin{array}{r}\text { Light Space اضو الَفضاء المتثير } \\
\text { Modulator }\end{array}$ & إسم العمل \\
\hline 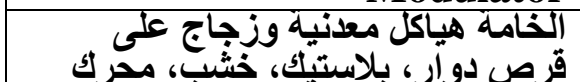 & الخامسة \\
\hline لى الميكانيكى & التقنيه \\
\hline برلين & مكان العمل \\
\hline 1930 & سنه الإنت \\
\hline
\end{tabular}

1- http://www.theartstory.org/artist-calder-alexander-artworks.htm\#pnt_3

2- http://www.georgerickey.org/works.html

3-https://www.tate.org.uk/art/artworks/tinguely-debricollage-t03822

4-https://www.harvardartmuseums.org/art/299819
شكل (3)

\begin{tabular}{|c|c|}
\hline جين تينظلى & |اسم الفنان \\
\hline Débricollage & إسم العمل \\
\hline كعاديائي مختلفه وخشب وبلاستيك ومحرك & \\
\hline ركى الميكانيكى & آلتقنيه \\
\hline 70×51× 46 سنتيمتر & |بعاد العمل \\
\hline $\begin{array}{l}1970 \\
20\end{array}$ & سنه الإنتاج \\
\hline
\end{tabular}

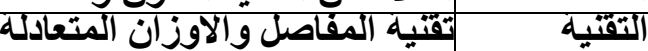

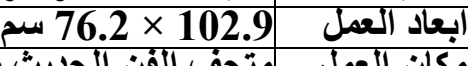

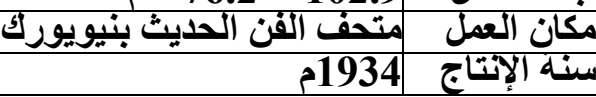

شكل (2)

\begin{tabular}{|c|c|}
\hline جورج ريكى & |سم القنان \\
\hline Crucifera III & العمل \\
\hline |إستانلس إستيل & \\
\hline تقنيه المحاور والتوازن المتعادل & \\
\hline 63,5 × 172,72 ×0,9 سنتيمتر & \\
\hline |متحف الفن بقلوريدا & \\
\hline
\end{tabular}




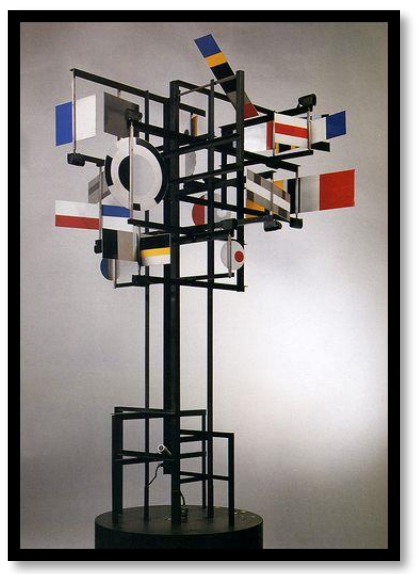

1 (5) شكل

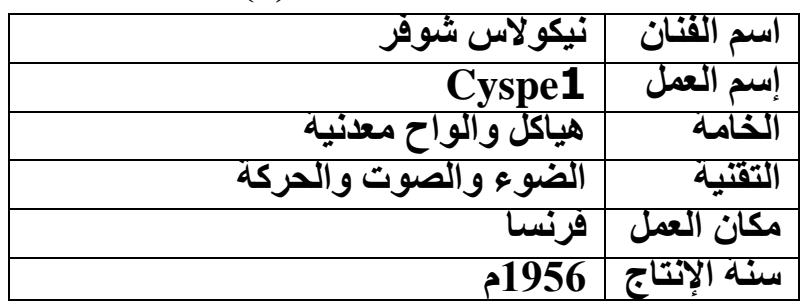

شكل (6)2

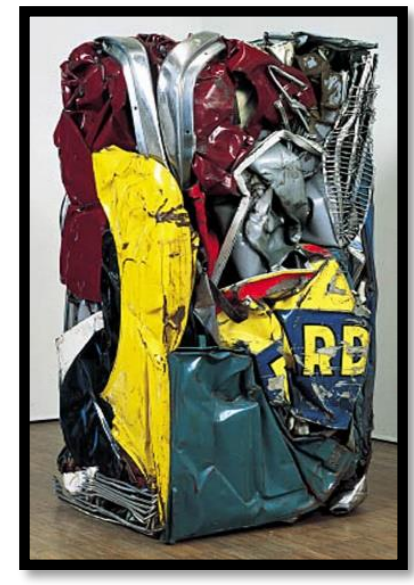

\begin{tabular}{|c|c|}
\hline سيزار بالاكينى & اسم الفنان \\
\hline 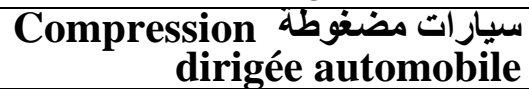 & إسم العمل \\
\hline معادن مختلفه & الخامه \\
\hline تقتيه الضغط الهيدروليكى & التقتية \\
\hline الابعاد 153 ×73 ×65 سنتيمتر & ابعاد العمل \\
\hline متحف الفن الحديثُ بباريس & مكان العمل \\
\hline 1962 & الإنتاج \\
\hline
\end{tabular}

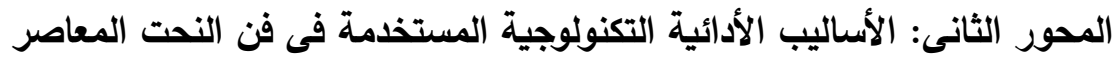

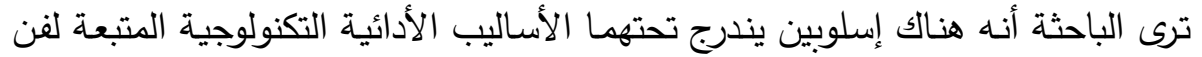

$$
\text { النحت المعاصر وهما: }
$$

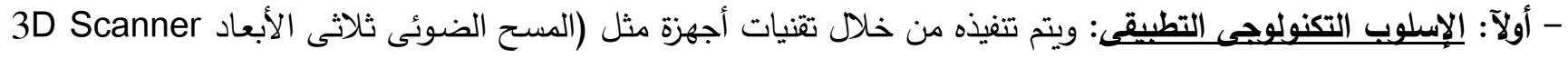
- تقنية النحت بالماء CNC Water Machine)

- Video Sculpture ثانيآ: الإسلوب التكنولوجى الإفتراضس: ويتم تطبيقة من خلال تقنيات أجهزة مثل (نحت الفيديو) -

$$
\text { أولآ: الإسلوب التكنولوجى التطبيقى }
$$

الهولوجرام Hologram).

- تقنية المسح الضوئيى ثلاثى الأبعاد 3D Scanner:

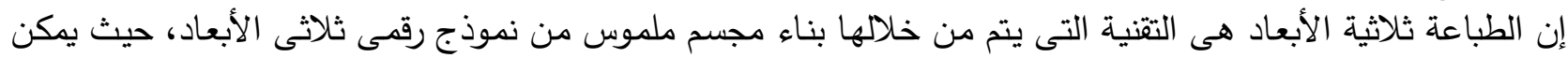

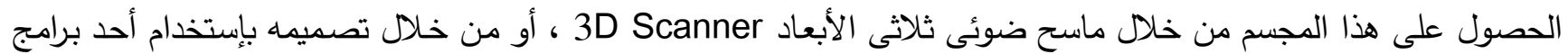

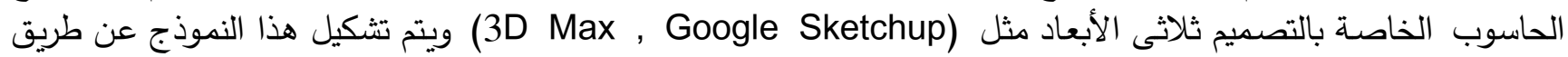

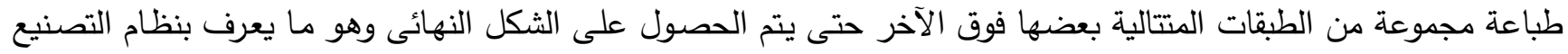

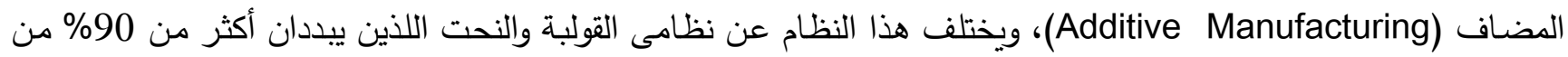
المادة المستخدمة فى التنفيذ.

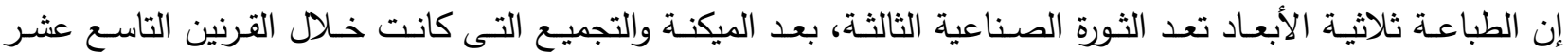

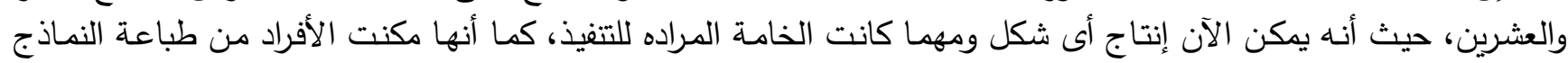

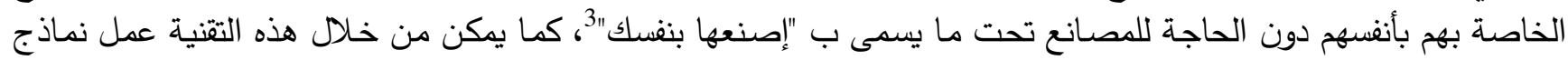

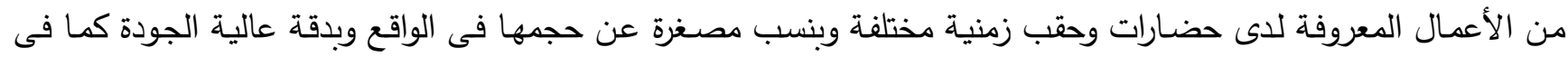
- https://www.youtube.com/watch?v=TTCiOoedUco

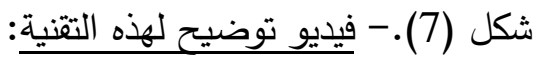

1- http://cyberneticzoo.com/cyberneticanimals/1956-cysp-1-nicolas-schoffer-hungarianfrench/

2- http://cesarbaldaccini.blogspot.com.eg/p/demarche.html

${ }^{3}$-https://ar.wikipedia.org 
- تقنية النحت بالماء Sculpture With Water:

يعد النحت بالماء من التقنيات المعاصره التى تستخدم فى فن النحت وتقوم من خلال آلة

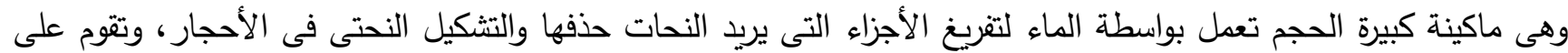

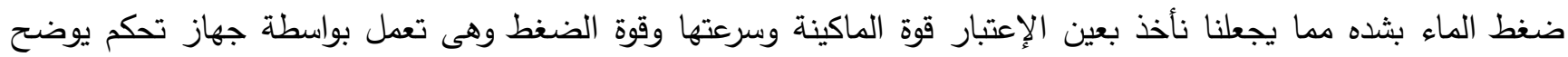
الأماكن المطلوب حذفها من خلال برامج على الحاسب الآلى متصله بالآلة مما يخدم النحات ويسهل عليه النحت الآلى وهذا

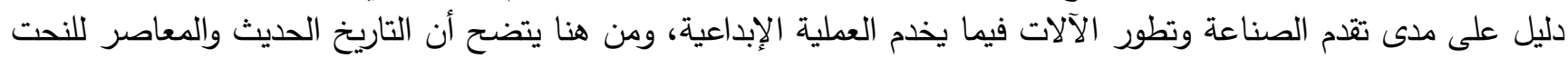

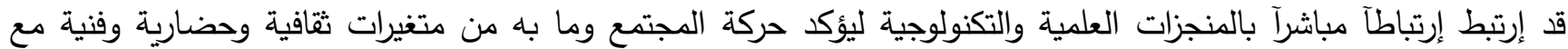

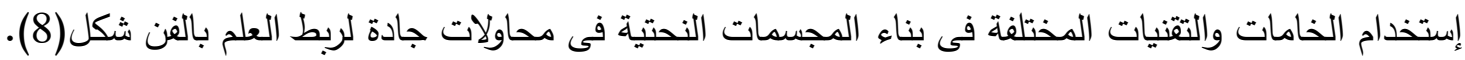
- https://www.youtube.com/watch?v=acU9Bw4uMCc

- فيديو توضيح لهذه التقنية: ثانياً : الإسلوب التكنولوجى الإفتراضى

- نحت الفيديو Video Sculpture: تقوم هذه التقنية على توظيف كاميرات الفيديو والكمبيوتر كوسائط لعرض نحت الفيديو فى عدد من العروض بواسطة

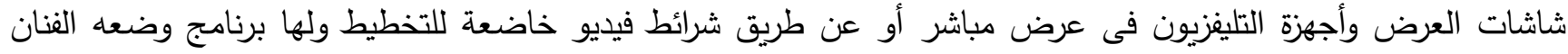
لإثارة الجمهور بالفكرة عن طريق العمليات الإليكترونية الصادرة للصوت والصورة، وقد تكون هذه التثنية إتجاه من الفنانين

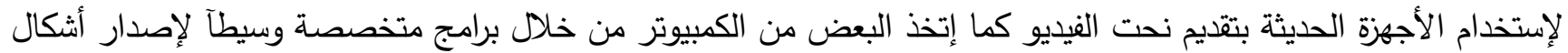

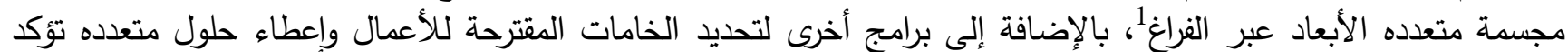

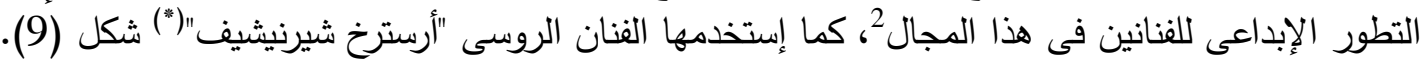
- https://vimeo.com/110937131

$$
\text { - https://vimeo.com/30108920 }
$$

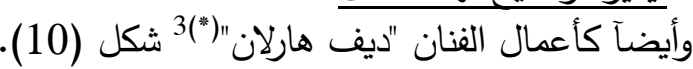
- فيديو توضيح لهذا العمل: - فيديو توضيح لهذا العمل: - الهولوجرام والنحت الضوضئُ لئى ( الليزر):

\section{Hologram \& Sculpture Photosynthetic (Laser)}

وقد إستخدم فيه الفنان نتائج التقدم التكنولوجى فى مجال الفيزياء للتصوير الضوئى وإستخدم أشعة الليزر فى إنتاج أشكال

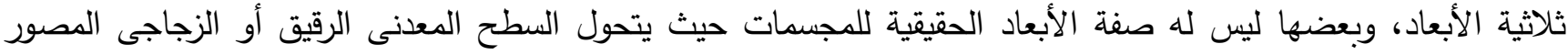

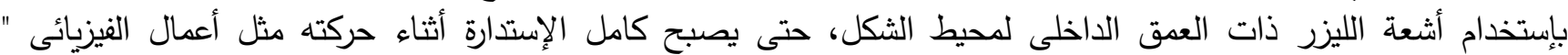

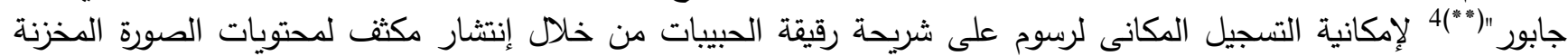

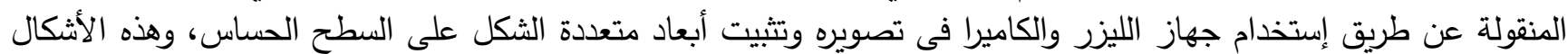
لها مقومات العمل المجسم فى الفراغ، ولكن من خلال وسيط ضوئى وطرق تكنولوجية مركبة فى عملية التصوير وقد عرفت هذه

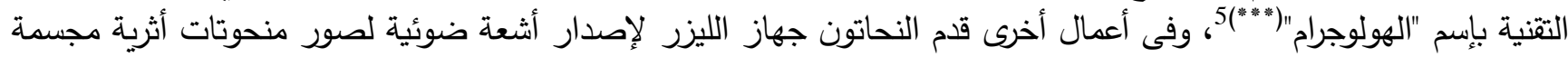
من فوق المبانى فى السماء، لتشكل أشكالآ ضوئية متحركة فى الفراغ الحقيقى كمنحوتات ضوفئية ونية ويتم التنظيم والتحكم فى حركته

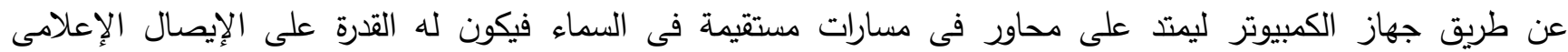

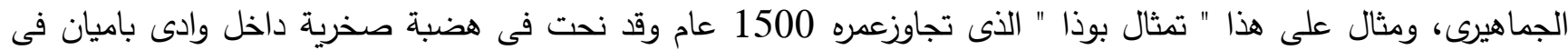

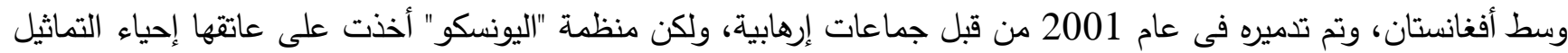

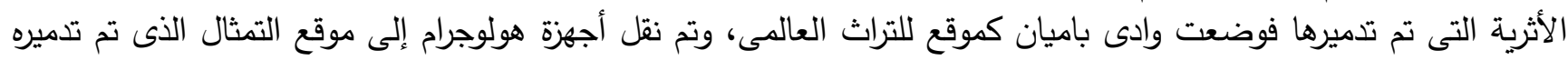

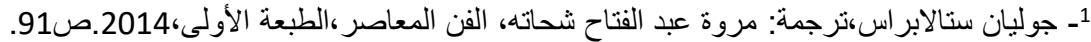

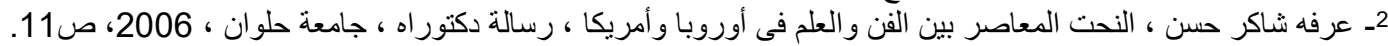

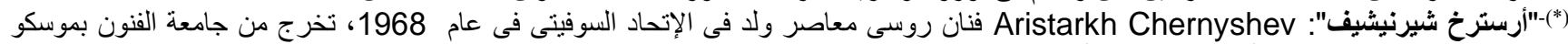

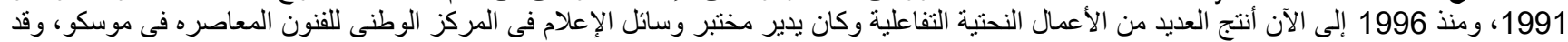

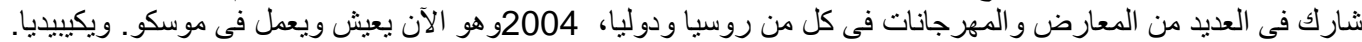

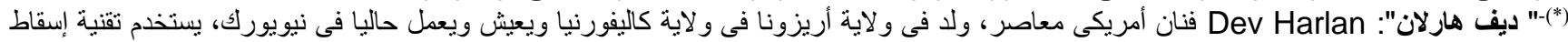
الضوء و الفيديو على منحوتانتانه. ويكيبيديا.

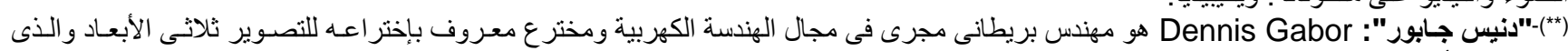

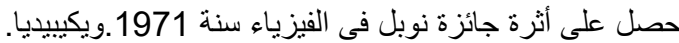

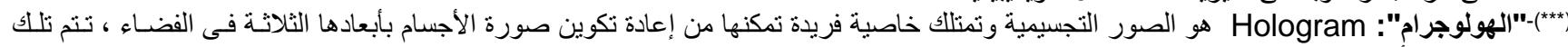


فكان بمثابة ولادة جديدة للتمثال عن طريق إسقاط صورة ثلاثية الأبعاد له فى نفس المكان الأصلى وكان بإرتفاع 175 قدم كما - https://www.youtube.com/watch?v=5CkeDuKLWd

\section{(أشكال المحور الثانى )} فى شكل (12)1. - فيديو توضيح لهذه التقنية:
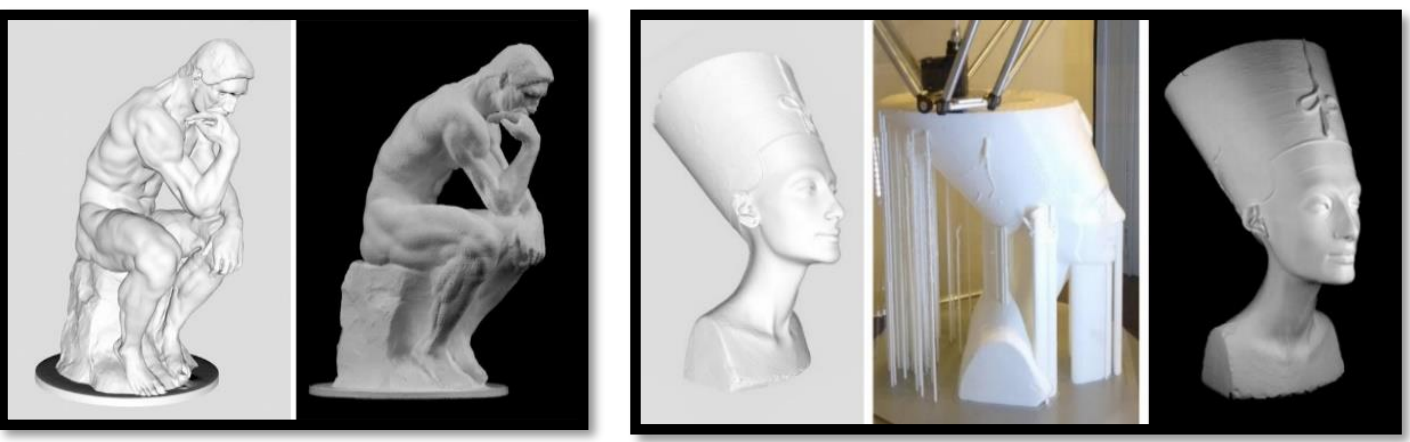

\begin{tabular}{|c|c|}
\hline 1880م للفنان اوجست رودان & إسم العمل \\
\hline طباعه تلاتيه الابعاد & التقتيه \\
\hline
\end{tabular}
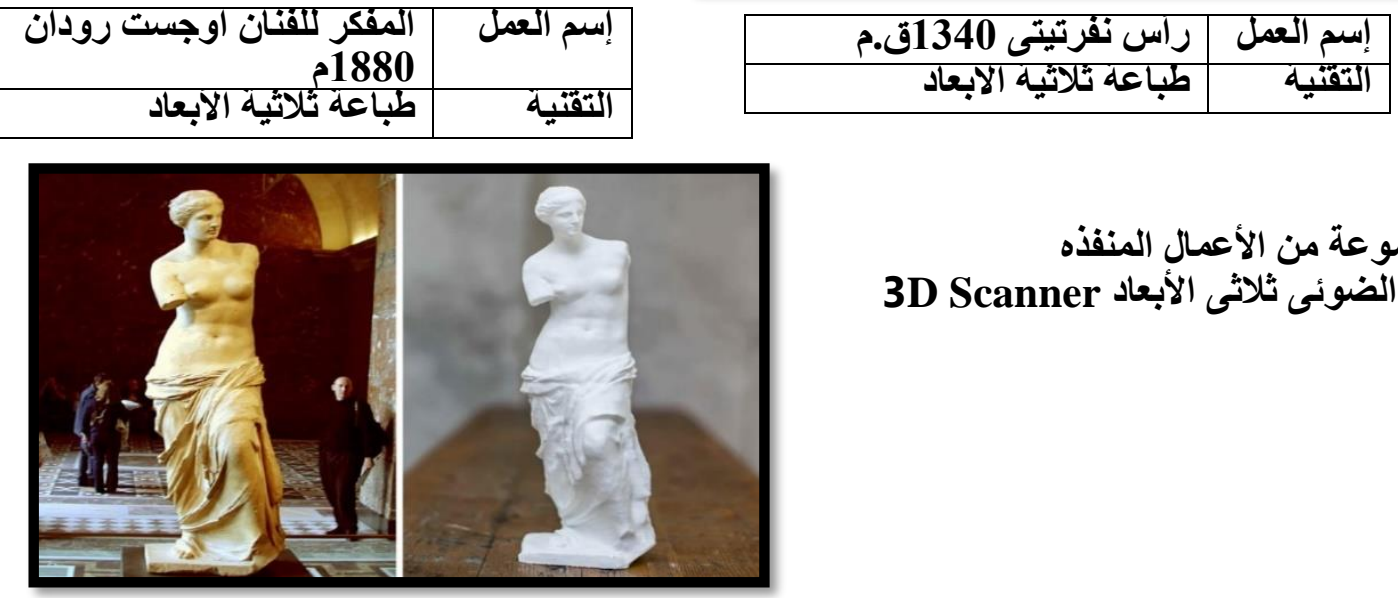

شكل (7) مجموعة من الأعمال المنفذه

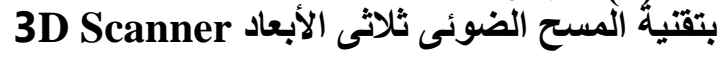

\begin{tabular}{|c|c|}
\hline ب دي ميلو للفنان الكسندروس انطيوك 101 ق.م & إسمب العمل \\
\hline تلاتيّه الابعاد & ألتقنيه \\
\hline
\end{tabular}
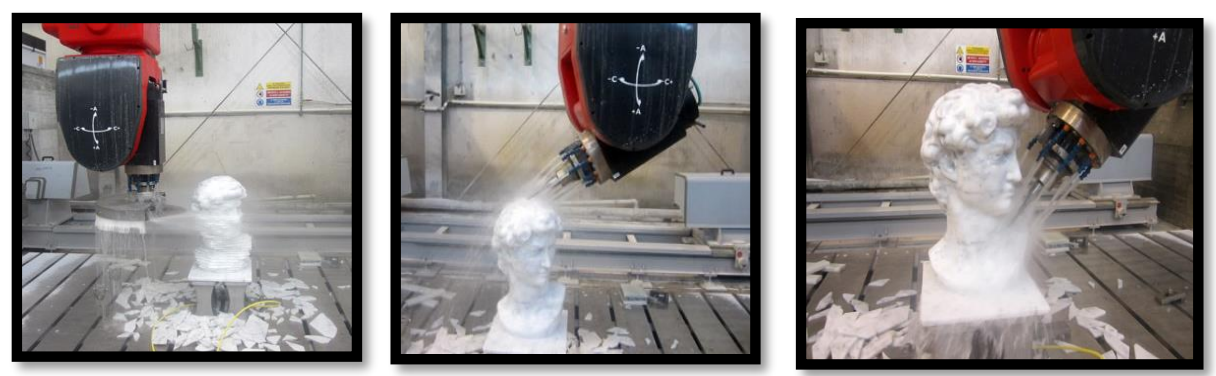

3 شكل (8)

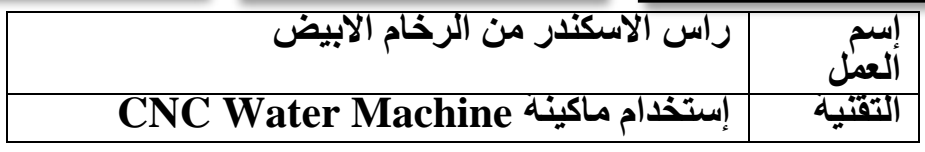

4 شكل (9)

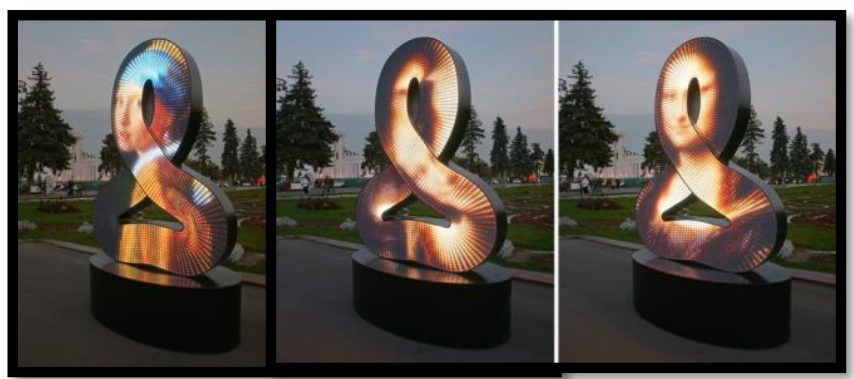

\begin{tabular}{|c|c|}
\hline ارسترَخ شُيرنيثُيف & اسم القنان \\
\hline Userpic & إسم العمل \\
\hline شُشاشه 8 LED انش & ألخامه \\
\hline بتقنيةٍ الفيديور للوحات عالميه & التقتيه \\
\hline موسكو & مكان العمل \\
\hline 2014 & سنـه الإنتاج \\
\hline
\end{tabular}

\footnotetext{
1-http://www.dailymail.co.uk/news/peoplesdaily/article-3124580/Chinese-millionaires-create-amazing-175-foot-3-D-hologram-AfghanBuddha-statue-destroyed-Taliban-bomb-blast.html

2- https://mymodernmet.com/free-3d-models-scan-the-world/

3- https://fabshopmachines.blogspot.com/2012/12/breton-contourfive-nc-700-cnc-machining.html

4- http://www.fubiz.net/en/2014/11/12/video-sculpture/
} 

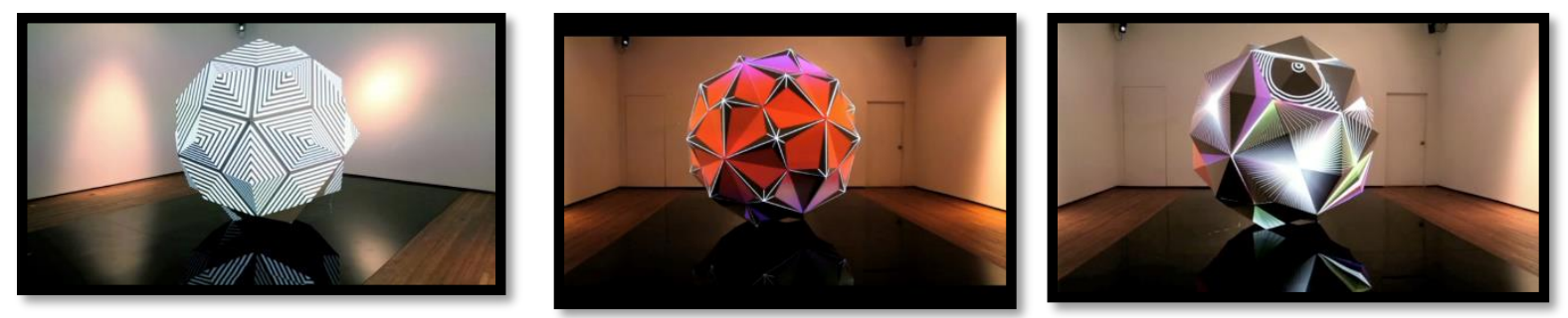

$\underset{1(10)}{\text { شكل }}$

\begin{tabular}{|c|c|}
\hline ديف هارلان & اسم الفنان \\
\hline بارمنيدس Parmenides & 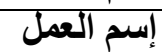 \\
\hline فُوم - خُّب - جبس & الخامهة \\
\hline عرض فيديو & الآقنيه \\
\hline نيويورك & مكان العمل \\
\hline 22011 & سنـه الإنتاج \\
\hline
\end{tabular}
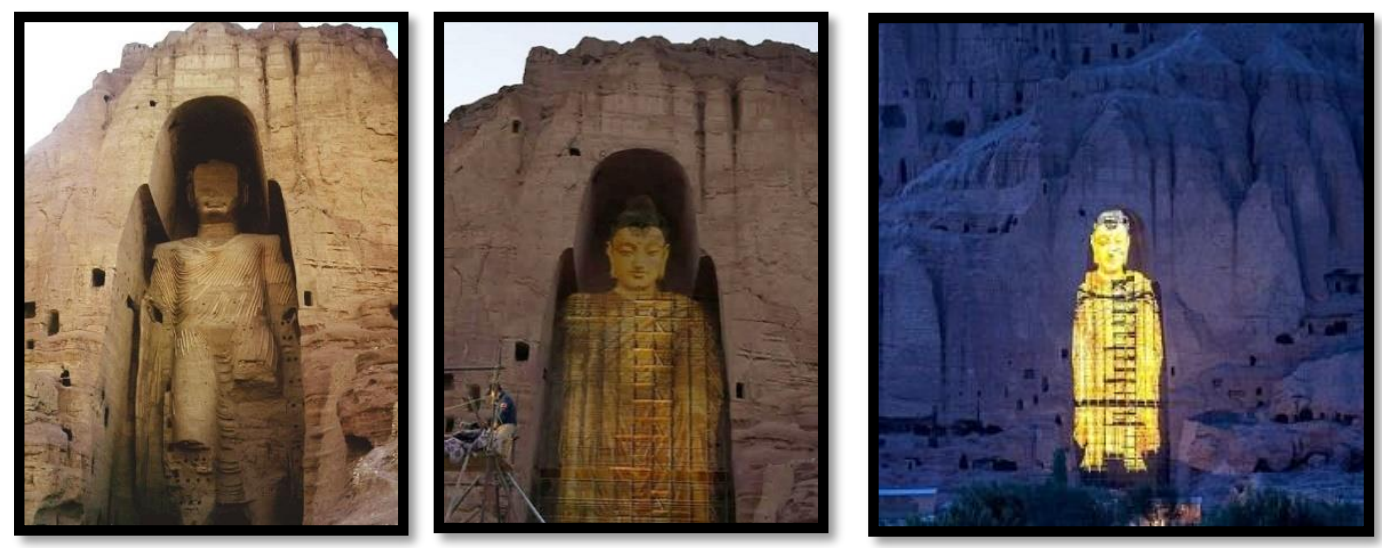

شكل (11)

\begin{tabular}{|c|c|}
\hline تمثال بوذا & 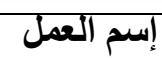 \\
\hline إسقاط صوره نتلاتيه الابعاد بتقنيه الهولوجرام & ألتقيه \\
\hline وادى باميان بافغانستان & \\
\hline إرتفاع 175 فذم & حاد العمل \\
\hline
\end{tabular}

المحور الثالث: البعد الجمالى والتعبيرى لصياغات تكنولوجيا فن النحت

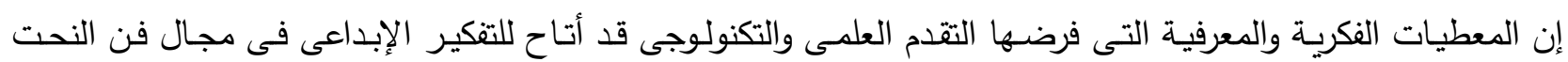

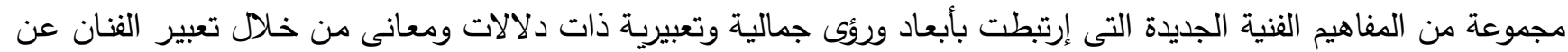

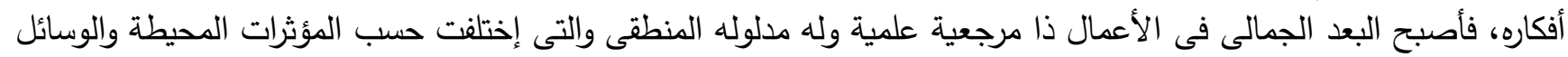

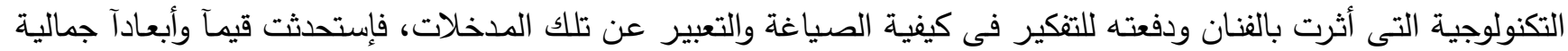

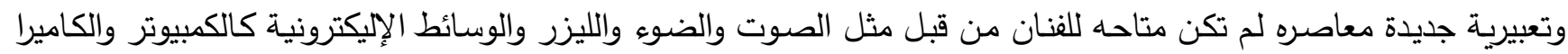

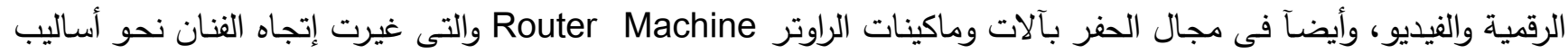

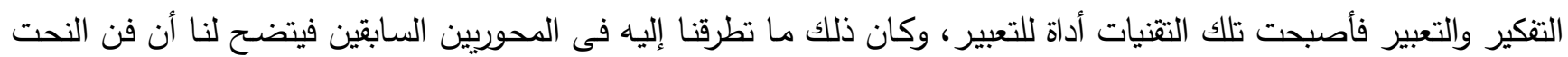

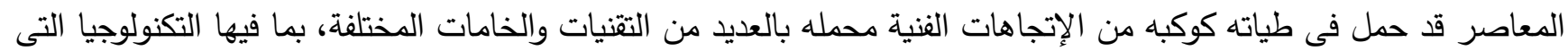
أصبحت كوسيط فنى فى أداء العملية الإبداعية فى الإتى العديد من الإتجاهية الفية العيد الفنية المعاصره.

إن التعبير عن مستحدثات التفكير العلىى من تكنولوجيا وإختراعات ومعارف وقوانين فى شكل تقنيات وصياغات جديدة أمرآ

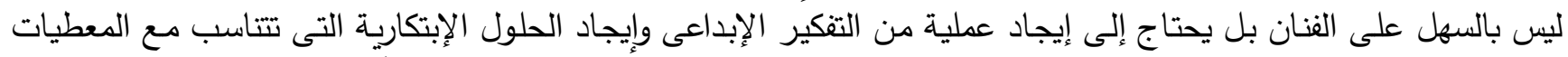

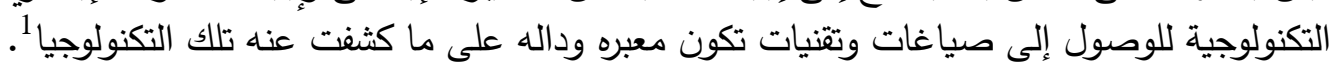

1-https://sofiliumm.wordpress.com/2011/10/23/parmenides-i-light-sculpture-by-dev-harlan/

2- http://www.dailymail.co.uk/news/peoplesdaily/article-3124580/Chinese-millionaires-create-amazing-175-foot-3-D-hologram-AfghanBuddha-statue-destroyed-Taliban-bomb-blast.html 


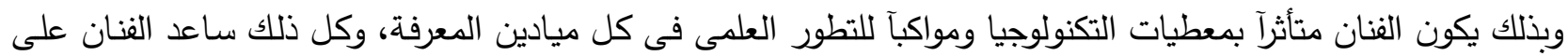

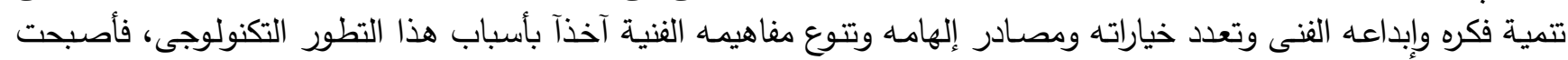

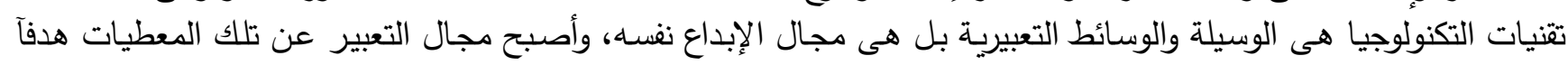

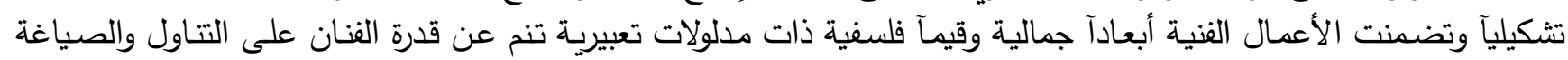
محققآ رؤى فنية معاصره.

نتـائج البحث :يمكنتا القول إن التقدم العلمى والتكنولوجى منذ النصف الثانى من القرن العشرين وحتى الآن قد مـر بمراحل

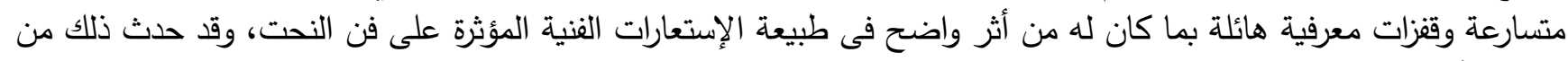

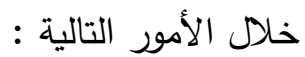

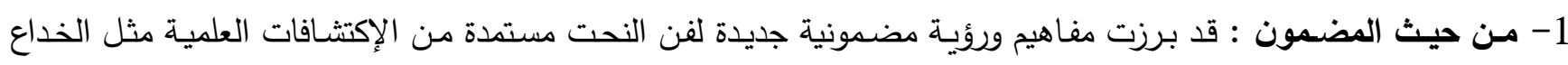
البصرى، والحدس الكومبيوترى، وعلاقة الحركة بالكتلة، وعلاقة الحركة بالزمن، والقوة المغناطيسية.

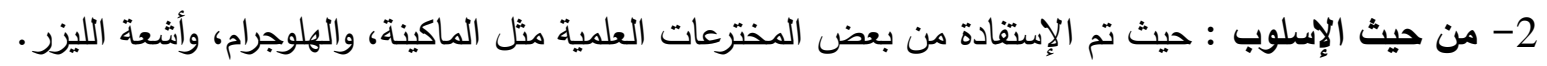

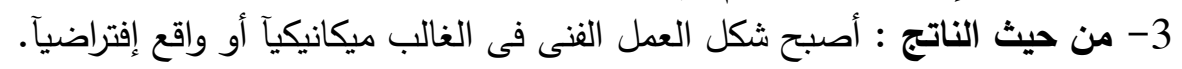

أنتائج والتوصيات: أولاً : أهم النتائج : النتيات :

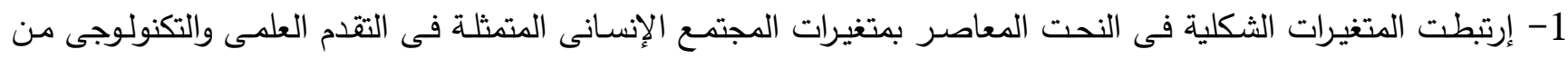

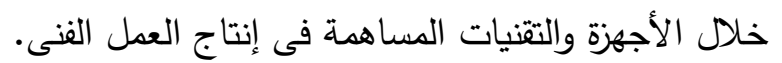
2- إثراء فن النحت من خلال الحلول التشكيلية الجديدة التى تتم بواسطة التجريب ومواكبه التقدم التكنولوجى للخامات والأدوات. 3- فى ظل تطبيق ونقل العلم للفن أصبح واضحآ نظرة الفنان المستقبلية نحو طرح مداخل ومنطلقات جديدة لتطوير مهاراته

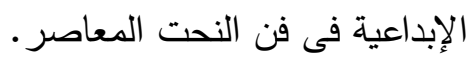
4- توجد علاقة ديناميكية بين العمل النحتى والتقنيات التكنولوجية فى فن النحت المعاصر . ثنانيا : التوصيات : 1- التوجه الفكرى نحو طرق تناول الوسائط التكنولوجية المختلفة التى تساهم فى مجال فن النحت لإثراء تجربة الفنان.

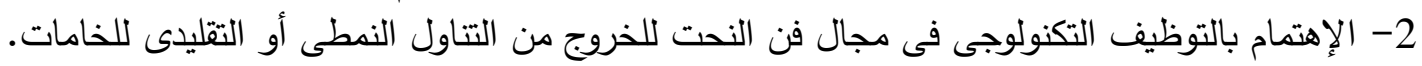
3- عمل ورش تجريبية للتعامل مع الأجهزة التكنولوجية المتاحة للكثف عن فن الأبعاد التثكيلية والجمالية الناتجة عن إستخدامها فى فن النحت.

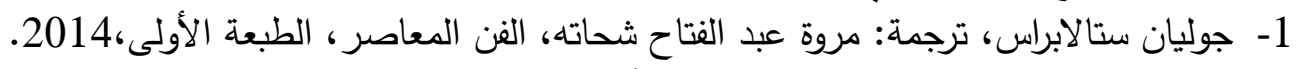

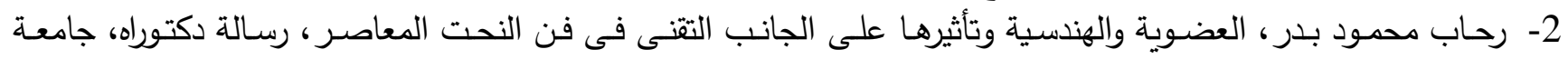
الأسكندرية، 2017.

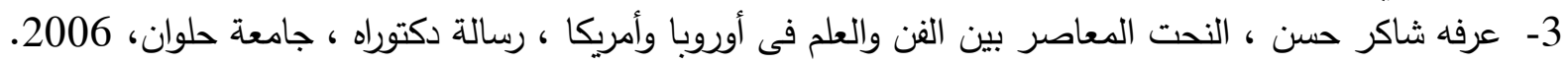

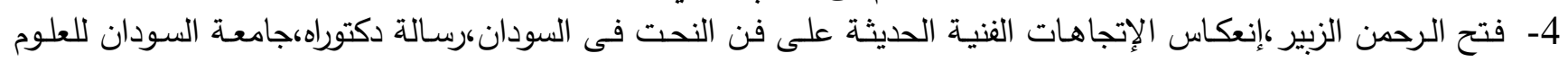
والتكنولوجيا،2017.

\section{- Second : Foreign References :}

1- Aranson,H.H:A history of Modern Art-PAINTING, Sculpture, Architecture, Thames and Hudson, London, 1969.

2- Cubism And Abstract Art,The Museum Of Modern Art ,New York,1936. 


\section{-Third : Internet Sites :}

1- https://www.youtube.com/watch?time_continue=52\&v=A5J6Qb11UHE

2- https://vimeo.com/275147732

3- https://www.youtube.com/watch?v=SrOA_GkRsNU

4- https://www.youtube.com/watch?v=nVnF9A3azSA

5- https://www.harvardartmuseums.org/art/299819

6- https://www.youtube.com/watch?v=gJD27tJLoaQ

7- http://cyberneticzoo.com/cyberneticanimals/1956-cysp-1-nicolas-schoffer-hungarianfrench/

8- http://www.theartstory.org/artist-calder-alexander-artworks.htm\#pnt_3

9- http://www.georgerickey.org/works.html

10- https://www.tate.org.uk/art/artworks/tinguely-debricollage-t03822

11- https://www.harvardartmuseums.org/art/299819

12- http://cyberneticzoo.com/cyberneticanimals/1956-cysp-1-nicolas-schofferhungarianfrench/

13- http://cesarbaldaccini.blogspot.com.eg/p/demarche.html

14- https://www.youtube.com/watch?v=TTCiOoedUco

15- https://ar.wikipedia.org

16- https://www.youtube.com/watch?v=acU9Bw4uMCc

17- https://vimeo.com/110937131

18- https://vimeo.com/30108920

19- https://www.youtube.com/watch?v=5CkeDuKLWdA

20- http://www.dailymail.co.uk/news/peoplesdaily/article-3124580/Chinese-millionaires-createamazing-175-foot-3-D-hologram-Afghan-Buddha-statue-destroyed-Taliban-bombblast.html

21- https://mymodernmet.com/free-3d-models-scan-the-world/

22- https://fabshopmachines.blogspot.com/2012/12/breton-contourfive-nc-700-cncmachining.html

23- http://www.fubiz.net/en/2014/11/12/video-sculpture/

24- https://sofiliumm.wordpress.com/2011/10/23/parmenides-i-light-sculpture-by-dev-harlan/

25- http://www.dailymail.co.uk/news/peoplesdaily/article-3124580/Chinese-millionaires-createamazing-175-foot-3-D-hologram-Afghan-Buddha-statue-destroyed-Taliban-bombblast.html 